
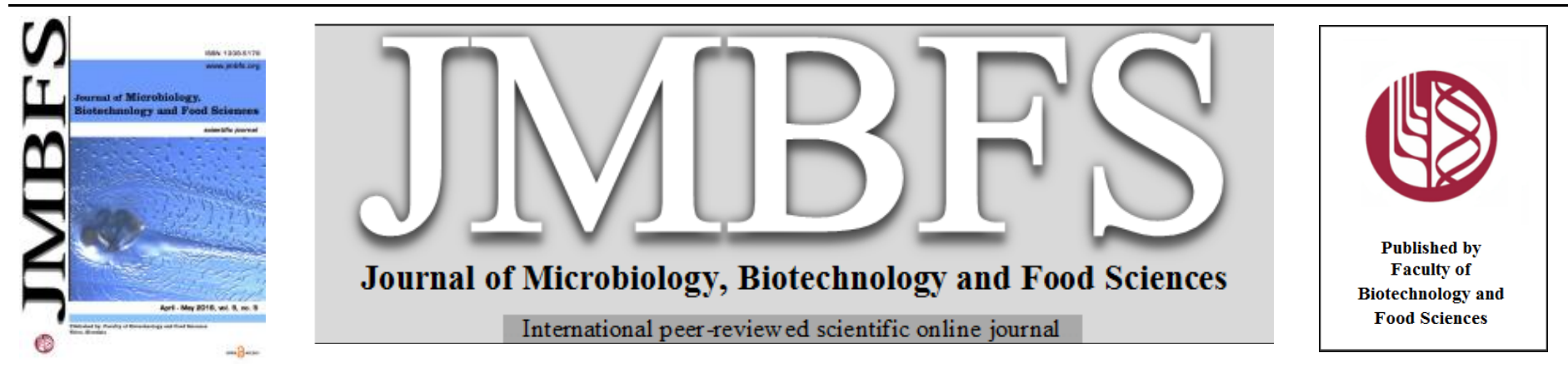

\title{
INFLUENCE OF RECONSTITUTION TEMPERATURE ON SURVIVAL OF CRONOBACTER SAKAZAKII IN POWDERED INFANT FORMULA
}

\author{
Kelsey C McEvoy, Carmel M Kealey and Damien B Brady*
}

$\operatorname{Address}($ es):

${ }^{1}$ Dept of Life \& Physical Science, Athlone Institute of Technology, Dublin Road, Athlone, County Westmeath, Republic of Ireland.

*Corresponding author: dbrady@ ait.ie

doi: 10.15414/jmbfs.2016.5.5.495-499

\section{ARTICLE INFO}

Received 1. 7. 2015

Revised 6. 1.2016

Accepted 6. 1. 2016

Published 1. 4. 2016

Regular article open $\partial_{\text {ACCESS }}$

\begin{abstract}
Cronobacter spp. are emerging opportunistic pathogens commonly associated with the feeding of powdered infant formula (PIF). This study aimed to investigate the ability of C.sakazakii (ATCC 29544) to survive heat injury in laboratory growth medium and powdered infant formula (PIF) in comparison to Escherichia coli (ATCC 25922) and other selected Cronobacter strains. As part of this work the thin agar layer (TAL) method for the recovery of heat-injured foodborne pathogens was evaluated for use with C.sakazakii (ATCC 29544) and E.coli (ATCC 25922). We report that heat treatment at $55^{\circ} \mathrm{C}$ for 10 minutes had no significant effect $(P>0.05)$ on C.sakazakii (ATCC 29544) viability in peptone or PIF. Significant differences in survival of Cronobacter strains after this heat treatment were identified indicating that heat tolerance in this genus may be strain dependent. PIF did not enhance survival of this organism in comparison to other media. Results indicate that a decrease in temperature of $5^{\circ} \mathrm{C}$ from the recommended $70^{\circ} \mathrm{C}$ for the reconstitution of PIF was sufficient to produce a significant increase in survival of C.sakazakii (ATCC 29544). Reconstituted PIF stored at room temperature was shown to support the survival and proliferation of this pathogen indicating that temperature abuse during PIF preparation and storage may significantly increase the risk of disease caused by these opportunistic pathogens.
\end{abstract}

Keywords: Cronobacter, powdered infant formula, heat-injury, thin agar layer

\section{INTRODUCTION}

PIF is consumed by millions of infants throughout the world every day, and is generally considered as safe (Pagotto \& Farber, 2009), however it is not a sterile product and can harbour pathogens such as Cronobacter, Salmonella and Staphylococcus (Wang et al., 2012). In 2004, the Food and Agriculture Organisation of the United Nations (FAO) and the World Health Organisation (WHO) jointly convened an expert meeting on Enterobacter sakazakii (now Cronobacter spp.) and other microorganisms in powdered infant formula (PIF) and concluded that intrinsic contamination of PIF with E.sakazakii (now Cronobacter spp.) and Salmonella has been a cause of infection and illnesses in infants. This includes severe disease which can lead to serious developmental sequelae and death (FAO/WHO, 2004). The World Health Organisation (WHO) recommends reconstitution of PIF using boiled water that has cooled slightly but not below a temperature of $70^{\circ} \mathrm{C}$. It is recommended that this be checked using a sterile thermometer (FAO/WHO, 2004). In contrast to this, manufacturers of this product most often recommend using boiled water which has been cooled for 30 minutes with no specific requirements given for exact temperature or recommended methods of checking temperature before reconstitution. A common risk factor in many reported Cronobacter (previously Enterobacter sakazakii) outbreaks is temperature abuse of reconstituted formula (Osaili \& Forsythe, 2009). Heating of prepared milk to $80^{\circ} \mathrm{C}-90^{\circ} \mathrm{C}$ or mixing with boiling water is likely sufficient to kill most microorganisms but is not recommended due to the potential loss of nutritional value, especially in terms of adverse effects on the vitamin content of PIF (Agostoni et al., 2004). It is currently recommended that reconstituted PIF be stored below $4^{\circ} \mathrm{C}$ and for no more than 4 hours (FAO/WHO, 2004) and that leftover product be discarded and never reheated or added to subsequent preparations (Osaili and Forsythe, 2009).

In 2007, a year-long study based on samples taken from a PIF processing plant, reported that the prevalence of the organism in specific locations of the plant was as high as $31 \%$ while the prevalence in the final product was $2.5 \%$. It was suggested based on these findings, other scientific studies and surveys from $\mathrm{FAO} / \mathrm{WHO}$, that PIF may be contaminated at frequencies ranging from $0-33 \%$ (Mullane et al., 2007). PIF and milk powder have been suggested as the main sources of Cronobacter infection and the vehicles responsible for $50-80 \%$ of infections caused by these organisms (Kim et al., 2008). Microorganisms in food processing or preparation environments are exposed to a wide range of chemical, physical and nutritional stresses (Osaili and Forsythe, 2009). The detection of food-borne pathogens should accommodate this by aiming to detect both normal and injured microorganisms. An injured cell has been defined as a cell that survives a stress but loses some of its distinctive qualities (Busta, 1978). In practical terms this means many injured cells will be capable of forming colonies on non-selective media, but not on selective media (Harstell, 1951) or may display an extended lag-phase in comparison to uninjured cells $(\mathbf{W u}, \mathbf{2 0 0 8})$. Therefore it is desirable to allow injured cells to recover before isolation or enumeration by customary procedures in order to avoid an underestimation of microbial content. The reader is directed to the review by $\mathbf{W u}(\mathbf{2 0 0 8})$ for a description of the numerous methods available for the recovery of injured bacterial cells. The method of recovery chosen for this study was the thin agar layer (TAL) method developed by Kang and Fung (2000). This one-step method is relatively convenient to prepare and use and has been utilised effectively to recover heat-injured Salmonella typhimurium (Kang and Fung, 2000). The method has been found to be more effective than selective media alone for the recovery of heat-injured foodborne pathogens due to its incorporation of an initial exposure to non-selective medium (Wu \& Fung, 2001). This present study includes an evaluation of the TAL method for the recovery of heat-injured C.sakazakii (ATCC 29544) and E.coli (ATCC 25922) cells.

It is not clear how stringently the guidelines for the safe preparation and storage of PIF are complied with in the home and hospital settings and education of potential users of PIF therefore remains paramount to ensure its safe preparation and the avoidance of outbreaks of infectious disease (FAO \& WHO, 2004). The inconsistencies existing in the recommendations for the safe preparation of PIF may prove to be extremely important in terms of preventing infection from intrinsic microorganisms, as even low numbers of organisms in this genus are considered to be a risk factor (FAO \& WHO, 2004). This present study compares the efficacy of currently recommended preparation methods in terms of ability to reduce survival of C.sakazakii (ATCC 29544) cells added at the time of preparation. In addition to the inconsistencies existing in the preparation guidelines for PIF, there are also discrepancies in the existing literature related to the Cronobacter genus. Differences in growth characteristics and tolerance to environmental stresses such as temperature resistance are reported to be strain dependent in some studies (Osaili \& Forsythe, 2009; Strydom et al., 2012) and 
characteristic of the entire genus in others (Iversen et al., 2004; NazarowecWhite \& Farber, 1997b). This issue is further confounded by the relatively recent taxonomic reclassification of this organism from a single species (Enterobacter sakazakii) to the novel genus Cronobacter (Iversen et al., 2008) Comprehensive studies published prior to this reclassification lack species specific data needed to describe the genus, now containing seven individua species (Joseph et al., 2011). The disparities in the available information on this group of pathogens emphasise the need for research such as the present study which compares multiple strains and species of Cronobacter in order to gain data with practical applications.

\section{MATERIAL AND METHODS}

\section{Source of Bacterial Strains and Growth Conditions}

Type strains of Cronobacter sakazakii (ATCC 29544), Escherichia coli (ATCC 25922) and Cronobacter muytjensii (ATCC 51329) were obtained from the American Type Culture Collection (ATCC), Virginia, USA. Type strains of Cronobacter turicensis (DSM 18703) and Cronobacter malonaticus (DSM 18702) were obtained from the German Collection of Microorganisms and Cel Cultures (DSMZ), Braunschweig, Germany. Additional strains of C.sakazaki (ATCC 29004, ATCC 12868) were also obtained from the ATCC. C.sakazaki (NCTC 8155) was obtained from the National Collection of Type Cultures (NCTC), Salisbury, UK. It should be noted that this strain is currently named Enterobacter sakazakii in the collection but was reclassified as C.sakazakii afte the recent taxonomic change (Iversen et al., 2008). All strains used in this study were stored in a Microbank ${ }^{\mathrm{TM}}$ (Pro-Lab Diagnostics) at $-80^{\circ} \mathrm{C}$. Fresh culture were obtained by direct inoculation of Nutrient Agar (Cruinn Diagnostics, Dublin, Ireland) formulated according to ISO 6579:2002, ISO 10273:2003 and ISO 16654:2001 and tested in accordance with ISO/TS 11133-2:2003. Liquid cultures were obtained by direct inoculation of Nutrient broth (Cruinn Diagnostics, Dublin, Ireland). Inoculated media were incubated overnight at $37^{\circ} \mathrm{C}$. Pure cultures on solid media were stored at $4^{\circ} \mathrm{C}$ for no more than 2 weeks. All culture media were obtained from Cruinn Diagnostics unless otherwise stated.

\section{Preparation of TAL plates}

The chosen selective media, Harlequin CSA-DFI-Cronobacter sakazakii AgarDFI Formulation and Harlequin E.coli/Coliform Medium, were prepare according to the manufacturer's instructions. The TAL plates were prepared according to the method described by Kang and Fung (2000) using tryptone soya agar (TSA) as a non-selective medium.

\section{Thin agar layer method evaluation}

Overnight cultures of all bacterial strains were prepared in nutrient broth and diluted in sterile peptone water to an optical density of $0.08-0.13$ at $625 \mathrm{~nm} .5 \mathrm{ml}$ aliquots of sterile peptone water were heated and maintained at $55^{\circ} \mathrm{C}$ or $70^{\circ} \mathrm{C}$ in a water bath. $50 \mu \mathrm{l}$ of C.sakazakii or E.coli alone or a 1:1 mixture of C.sakazakii (ATCC 29544) and E.coli (ATCC 25922) were added to the heated peptone water. Inoculated samples were maintained at the specified temperatures for 10 minutes. After this time the samples were cooled quickly by placement in slush ice. $100 \mu 1$ of each sample was removed before and after the heat treatment and used to prepare serial dilutions for plating on the prepared solid media. The plates were incubated at $37^{\circ} \mathrm{C}$ for 24 hours after which time the visible colonies were counted.

\section{Establishment of reconstitution temperatures}

$500 \mathrm{ml}$ of distilled water was heated on a hot plate and allowed to boil for approximately 30 seconds and stood at room temperature. Water temperature was monitored using a thermometer and recorded every 5 minutes for one hour. This was repeated in triplicate and on three independent testing days in order to obtain average temperature values for specific time periods in the cooling process.

\section{Preparation of bacteria and PIF reconstitution}

Bacterial cultures were prepared and diluted as described previously. The concentration of PIF used was chosen from the table provided by the manufacturer as the concentration most suitable for feeding neonates $(0.75 \mathrm{~g} / 10$ $\mathrm{ml}$ water). $100 \mu \mathrm{l}$ of the diluted bacterial culture was added to the dry PIF immediately prior to the addition of water. The PIF was reconstituted using boiled water that had cooled to $70^{\circ} \mathrm{C}, 65^{\circ} \mathrm{C}, 60^{\circ} \mathrm{C}$ or $55^{\circ} \mathrm{C}$. Immediately after the addition of water at the specified temperatures $100 \mu \mathrm{l}$ of each sample was removed and used to prepare serial dilutions and spread plates on selective agar The remaining inoculated PIF samples were incubated at room temperature for 2 hours. The process of preparing serial dilutions and spread plates was repeated each hour. Plates were incubated at $37^{\circ} \mathrm{C}$ overnight before conducting colony counts and calculating $\mathrm{CFU} / \mathrm{ml}$ for each testing interval.

\section{Influence of PIF on survival rates}

Heat treatment using C.sakazakii (ATCC 29544) was performed according to the method previously described. Dilutions were plated on selective agar only and PIF was used alongside peptone for both $55^{\circ} \mathrm{C}$ and $70^{\circ} \mathrm{C}$ heat treatments. Six additional strains of Cronobacter were included for heat treatment in PIF at $55^{\circ} \mathrm{C}$ for 10 minutes in order to establish any differences in heat tolerance between particular strains of this organism.

\section{Statistical Analysis}

Results for all tests described were recorded and analysed using Microsoft ${ }^{\circledR}$ Excel Software. Methods of presenting the data obtained were chosen based on a literature review of similar studies. Statistical analysis was performed using the paired Student t-test. $P$ values $<0.05$ were considered significant, $P$ values $<0.01$ as very significant and $P$ values $<0.001$ as highly significant. Error bars on graphs represent \pm standard error of the mean (SEM).

\section{RESULTS}

\section{TAL method evaluation}

The thin agar layer (TAL) method was evaluated for the recovery of heat-injured C.sakazakii (ATCC 29544) and E.coli (ATCC 25922) in both pure and mixed cultures. The mixed culture experiments aimed to assess the TAL method in terms of its ability to retain the selective characteristics of the original selective medium i.e. inhibition of growth of other organisms and/or distinctive colour change in organism of interest. C.sakazakii produced characteristic circular cream to yellow colonies on the TSA plates as expected. E.coli (ATCC 25922) produces pale cream colonies of roughly the same size on this agar and distinguishing between the two species on the mixed culture plates was therefore difficult. The selective Cronobacter medium (DFI) produced colonies of a similar size to those on the TSA for C.sakazakii. The distinctive colour change of the colonies to dark green was clearly visible. This colour change did not occur in the E.coli colonies and they were also noticeably smaller than on the TSA plates, indicating that some inhibition of growth had occurred. The TAL plates produced the desired colour change but no inhibition of E.coli (ATCC 25922) was visible indicated by colonies of both species being of the same size. The quantity of bacteria recovered (represented by log colony forming units $/ \mathrm{ml}$ ) by each medium after heat treatment for 10 minutes at $55^{\circ} \mathrm{C}$ is illustrated in figure 1 . The same information for pure C.sakazakii (ATCC 25944) and mixed culture with E.coli (ATCC 25922) after heat treatment at $70^{\circ} \mathrm{C}$ for 10 minutes is provided in figure
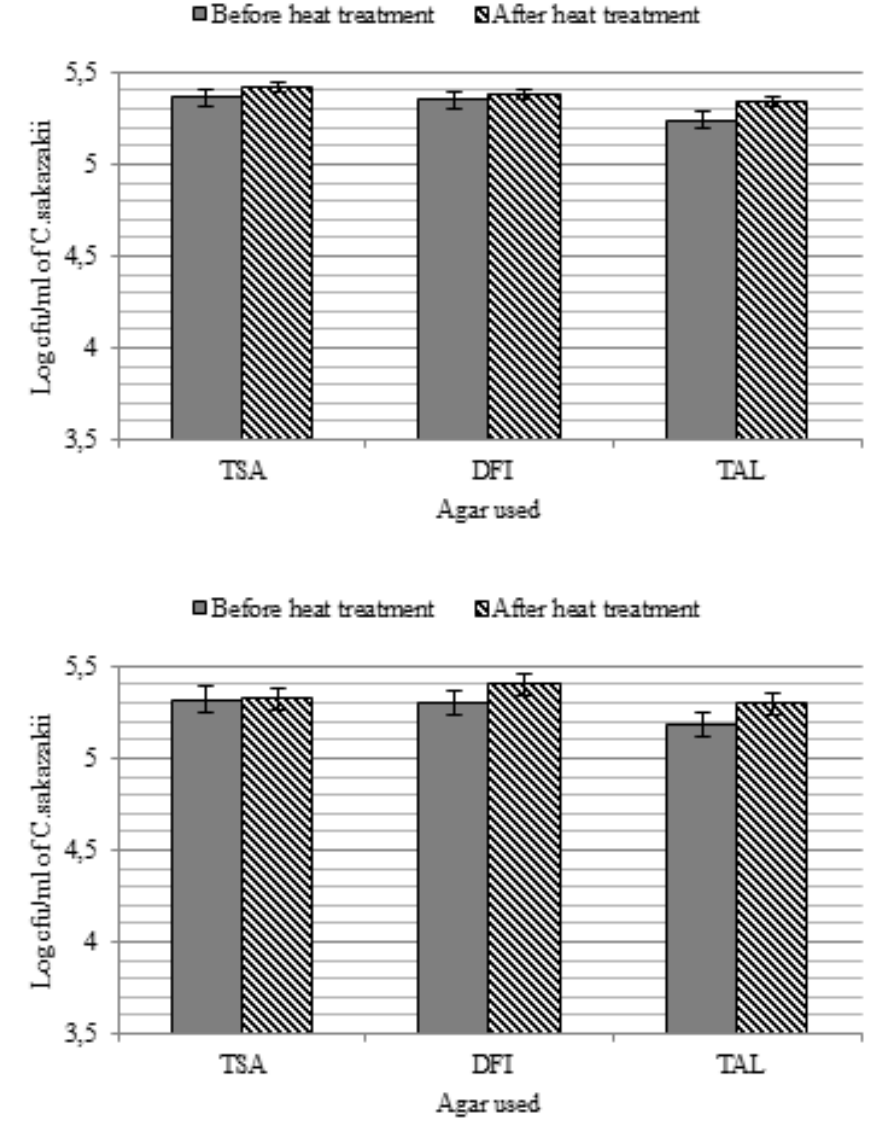
口Before heat treatment $\mathbf{N A f t e r}$ heat treatment

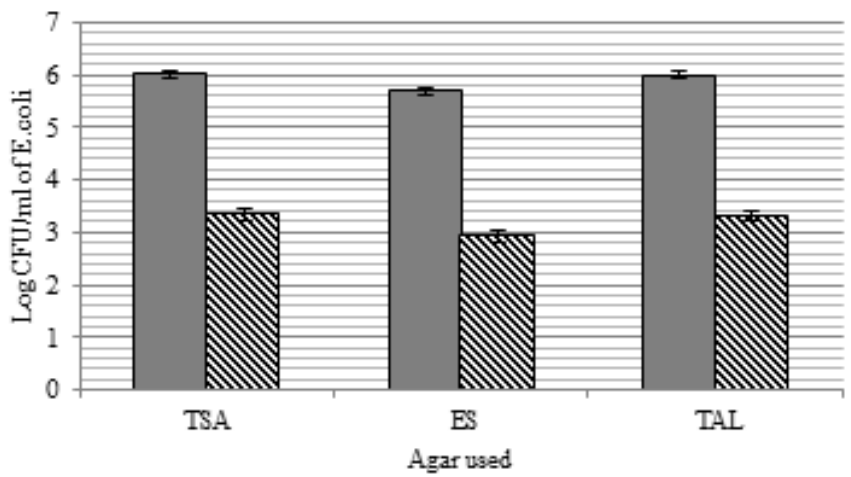

Figure 1 Log CFU/ml of C.sakazakii (ATCC 29544) in pure culture (A) and mixed culture (B) and E.coli (ATCC 25922) in pure culture (C) before and after heat treatment for 10 minutes at $55^{\circ} \mathrm{C}$. Tryptone soya agar (TSA), C.sakazakii selective agar (DFI), E.coli selective agar (ES) and thin agar layer plates (TAL)

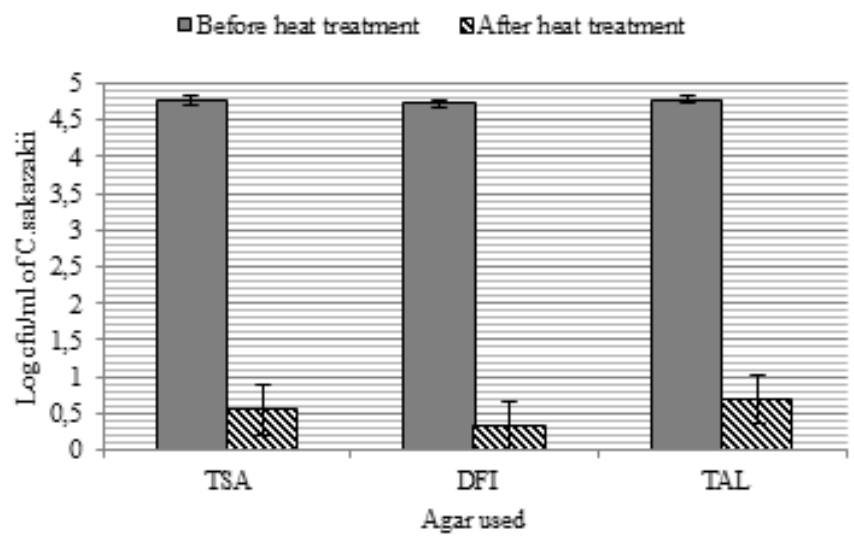

口Before heat treatment AAfter heat treatment

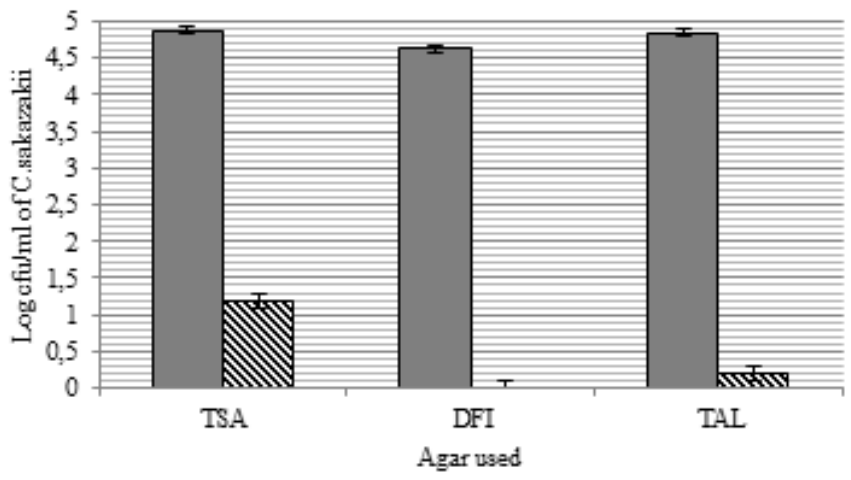

Figure 2 Log CFU/ml of C.sakazakii (ATCC 29544) in pure culture (A) and mixed culture (B) before and after heat treatment for 10 minutes at $70^{\circ} \mathrm{C}$ using tryptone soya agar (TSA), C.sakazakii selective agar (DFI) and thin agar layer method (TAL)

\section{Effect of PIF on C.sakazakii (ATCC 29544) heat-treatment surviva}

An investigation into the effect of PIF on bacterial survival of heat treatment for 10 minutes at $55^{\circ} \mathrm{C}$ and $70^{\circ} \mathrm{C}$ was carried out using C.sakazakii (ATCC 29544). The survival of this organism after these treatments was assessed in terms of log $\mathrm{CFU} / \mathrm{ml}$ of bacteria and is illustrated in figure 3 . This investigation was furthered by comparing the survival rates of six additional Cronobacter species after heat treatment for 10 minutes at $55^{\circ} \mathrm{C}$ in PIF. The results of this investigation are represented in figure 4.

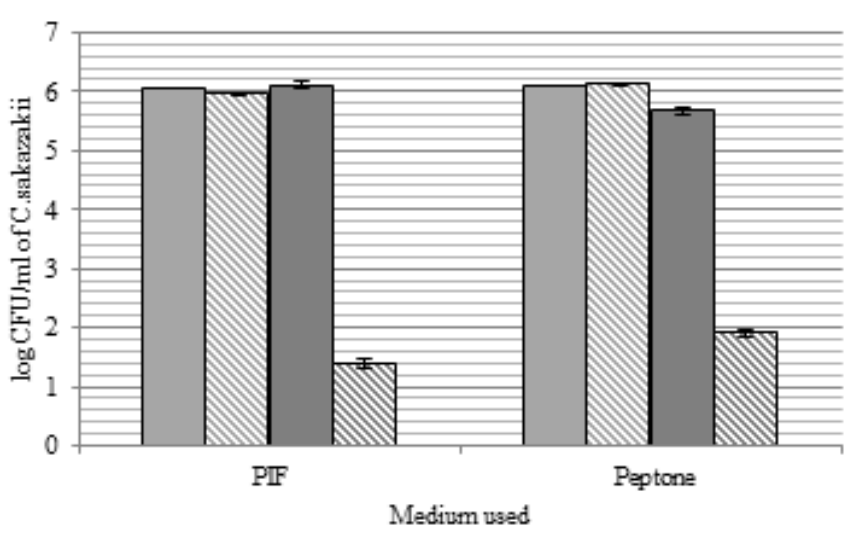

Figure $3 \mathrm{Log}$ CFU/ml of C.sakazakii (ATCC 29544) in PIF and peptone before heat treatment at $55^{\circ} \mathrm{C}$ (B HT 55), after heat treatment at $55^{\circ} \mathrm{C}$ (A HT 55), before heat treatment at $70^{\circ} \mathrm{C}\left(\mathrm{B}\right.$ HT 70) and after heat treatment at $70^{\circ} \mathrm{C}$ (A HT 70)

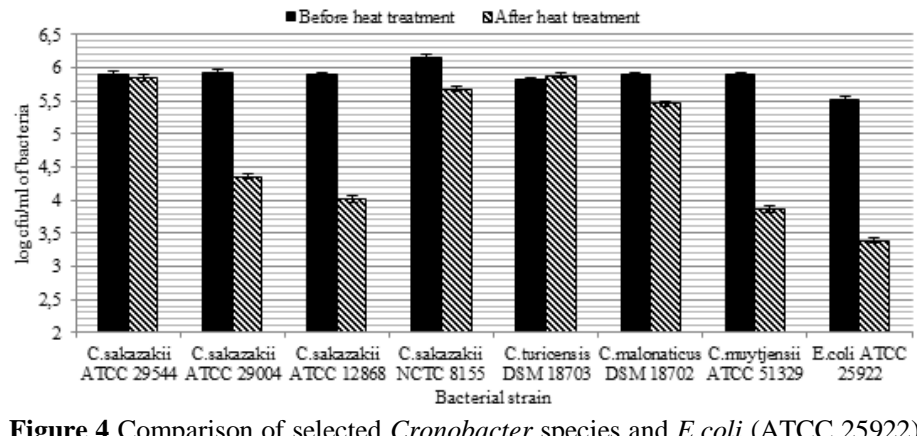

\section{Effect of PIF reconstitution method on C.sakazakii survival}

In accordance with the manufacturer's instructions for the preparation of PIF, it is recommended that boiled water be allowed to cool at room temperature for 30 minutes before use. An investigation was carried out in order to establish if this method complied with WHO recommendations which state that water should not be allowed cool below $70^{\circ} \mathrm{C}$ for the safe reconstitution of PIF (FAO/WHO, 2004). A number of temperatures within this range were then chosen to be used in a further investigation in which PIF was spiked with a known concentration of C.sakazakii (ATCC 29544) before reconstitution with water allowed to cool to set temperatures. Bacterial survival was assessed immediately and after one and two hours of standing at room temperature. The collected data are represented in figure 5 .

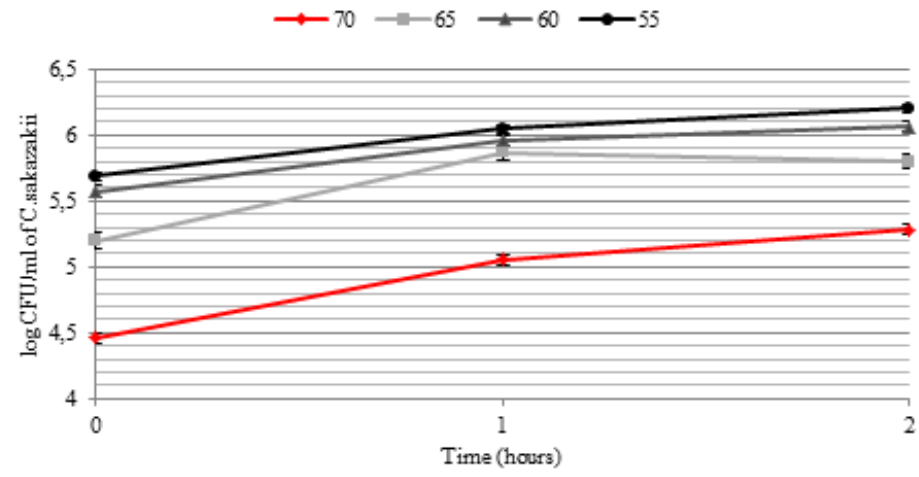

Figure 5 Survival and growth of C.sakazakii (ATCC 29544) after PIF reconstitution at a range of temperatures $\left(55^{\circ} \mathrm{C}, 60^{\circ} \mathrm{C}, 65^{\circ} \mathrm{C}, 70^{\circ} \mathrm{C}\right)$

\section{DISCUSSION}

\section{TAL method evaluation}

The TAL method was successful in producing colony colourization associated with the specific selective medium and facilitated superior identification between the bacteria compared to non-selective agar. However, the colonies of both species were much larger than on either the DFI or TSA plates, making counting 
considerably more difficult due to colonies merging with surrounding colonies. E.coli (ATCC 25922) colonies were similar in size to those of C.sakazakii (ATCC 29544) indicating a reduction/lack of inhibition that had been visible when using the selective agar alone. The TAL method has previously been shown to be effective in recovering more cells after heat-injury than selective agar alone in a number of foodborne pathogens. The method has been evaluated for a range of species including Salmonella typhimurium (Kang and Fung, 2000; Wu and Fung, 2001) Escherichia coli O157:H7, Listeria monocytogenes, Staphylococcus aureus and Yersinia enterocolitica (Wu and Fung, 2001) and recovered significantly more cells for each organism than the respective selective agar alone. Interestingly, the findings of this study do not correlate with previous studies in that there was no significant difference between the selective, nonselective and TAL agars in terms of number of bacteria recovered $(P>0.05)$ This was apparent in pure and mixed cultures and both before and after heat treatment for 10 minutes at $55^{\circ} \mathrm{C}$ (See figures 1 and 2). This experiment was repeated using TAL plates that incorporated agar selective for E.coli (Harlequin E.coli/Coliform Medium). As was observed in previous studies (Wu and Fung, 2000; Kang and Fung, 2001), a significant reduction in the number of viable E.coli cells occurred.

The World Health Organisation (WHO) recommends that water should be no less than $70^{\circ} \mathrm{C}$ for the reconstitution of powdered infant formula. This experiment was therefore repeated at this higher temperature to observe any effect on the recovery of C.sakazakii (ATCC 29544) cells. There was a very significant drop in bacterial numbers after treatment at this temperature for 10 minutes $(P<0.01)$ This finding was expected as it has been shown that exposure of species of Cronobacter to temperatures above $68^{\circ} \mathrm{C}$ for even short periods of time can significantly reduce the number of surviving cells (Nazarowec-White $\boldsymbol{\&}$ Farber, 1997a). The TAL method again did not recover significantly more cells than the other agars used $(P>0.05)$. In the mixed culture experiment the TSA produced significantly higher counts than the other agars $(P<0.05)$. The bacterial species used in this study share very similar colony morphology on this non-selective agar, increasing the likelihood of counting errors occurring. This agar is therefore not suitable for use in mixed culture assays and was included for comparison purposes only. It can be concluded that the TAL method for the recovery of heatinjured cells, in this case, is not significantly more effective than the use of selective agar alone. The volume of agar used and the added time for the preparation of plates for this method are therefore not justified. Further experiments utilised selective agar alone on the basis of these findings.

\section{The influence of medium on C.sakazakii (ATCC 29544) survival}

It has been suggested that the high total solids, fat and sugar content of PIF may have protective effects on bacteria during drying and reconstitution (Kim et al., 2008; Osaili \& Forsythe, 2009). This claim was investigated by comparing C.sakazakii (ATCC 29544) survival after heat treatment at $55^{\circ} \mathrm{C}$ and $70^{\circ} \mathrm{C}$ in PIF and peptone. After heat treatment at $55^{\circ} \mathrm{C}$ for 10 minutes, there was no significant drop in the number of C.sakazakii (ATCC 29544) recovered for either medium $(P>0.05)$. This correlates with the data generated previously from the TAL method evaluation. After heat treatment at $70^{\circ} \mathrm{C}$ for 10 minutes there was a highly significant drop in the number of cells recovered for both media $(P<$ $0.001)$. However there was no significant difference found between survival of C.sakazakii (ATCC 29544) in PIF and survival in peptone $(P>0.05)$. This is an indication that PIF does not incur any protective benefits in terms of prolonged survival at higher temperatures in a liquid medium. The composition of PIF may, however, improve the survival of Cronobacter spp. during desiccation. The desiccation resistance and persistence of these bacteria in infant formula has been reviewed previously (Osaili \& Forsythe, 2009) and will therefore not be discussed in detail here.

A notable finding of this study was that there was no significant drop in C.sakazakii (ATCC 29544) numbers after the heat treatment at $55^{\circ} \mathrm{C}(P>0.05)$, The five foodborne pathogens mentioned that have been previously used to evaluate this method, all dropped significantly in terms of CFU $/ \mathrm{ml}$ after the heat treatment step described (Wu and Fung, 2001; Kang and Fung, 2000). It has been shown that C.sakazakii has an array of survival mechanisms which include resistance to desiccation and osmotic stresses, in particular the ability to synthesise a capsule under certain conditions (Osaili and Forsythe, 2009). This may explain the apparent lack of effect observed for the heat treatment step used here. This was investigated further by repeating the heat treatment at $55^{\circ} \mathrm{C}$ for 10 minutes with the inclusion of six additional strains of Cronobacter and the type strain, E.coli (ATCC 25922). This was done in order to establish any differences between strains in terms of heat tolerance at this temperature in PIF. As shown in figure 4 , the tolerance to heat treatment at this temperature was not present in all strains of Cronobacter. Four out of the seven strains tested were not affected or showed only a slight decrease in number after the treatment while C.sakazaki (ATCC 29004), C.sakazakii (ATCC 12868) and C.muytjensii (ATCC 51329) numbers were significantly reduced $(P<0.05)$ by the heat treatment. It has previously been reported that thermal resistance in this genus is strain dependant (Strydom et al., 2012) but in contrast to these findings, other studies have reported no significant difference between strains (Iversen et al., 2004). This inconsistency in findings to date highlights the importance of studies such as the one conducted here in terms of elucidating the survival and growth characteristics of these organisms in PIF.

It has previously been shown that pasteurisation is sufficient to eliminate Enterobacteriacae including Cronobacter spp. (Lin \& Beuchat, 2007). One potential route of entry into the powdered infant formula (PIF) production line and/or the products is the post-pasteurisation addition of plant-derived supplements such as starches and proteins, that are potentially contaminated with Cronobacter spp., without the use of an additional heating step (Schmid $\boldsymbol{e t}$ al., 2009). Some studies have suggested that the high prevalence of Cronobacter spp. in PIF may be, in part, due to an unusually high tolerance to dry conditions. This is thought to be inferred by the organism's ability to produce trehalose. Trehalose is a compatible solute which protects bacteria from dry conditions by stabilising phospholipid membranes and proteins (Kim et al., 2008). While the importance of trehalose production has not yet been fully elucidated, it is clear that the organism has an array of survival mechanisms which includes resistance to desiccation and osmotic stresses, in particular the ability to synthesise a capsule under certain conditions (Osaili and Forsythe, 2009). It is possible that the findings of this study, showing that some strains possess a tolerance to the heat treatment described, may be due to the presence of such an ability or mechanism. Further research into the cause of the observed tolerance to heat treatment and the reasons for its absence in certain strains of Cronobacter may yield useful insights into the control and prevention of infections caused by the presence of these organisms in PIF.

Influence of reconstitution temperature on C.sakazakii (ATCC 29544) survival and growth in PIF

As previously stated, the World Health Organisation (WHO) recommends reconstitution of PIF using boiled water that has cooled slightly but not below a temperature of $70^{\circ} \mathrm{C}$. It is recommended that this be checked using a sterile thermometer (FAO \& WHO, 2004). Manufacturers of PIF most often recommend using boiled water which has been cooled for 30 minutes before use for the preparation of PIF. In order to compare these methods in terms of C.sakazakii (ATCC 29544) survival in reconstituted PIF an average temperature for water cooled at room temperature for 30 minutes was calculated. On average after 30 minutes of cooling the water had cooled to $68^{\circ} \mathrm{C} \pm 2.9^{\circ} \mathrm{C}$. A standard volume $(500 \mathrm{ml})$ and controlled conditions were used in this experiment but it can be presumed that in the home/hospital setting the volume of water and the size and type of container used would also have an effect on the rate of cooling and increase the variability of the rate of cooling. A range of temperatures were therefore selected for testing $\left(55,60,65\right.$ and $\left.70^{\circ} \mathrm{C}\right)$.

As expected, the addition of water cooled to $70^{\circ} \mathrm{C}$ caused an immediate and highly significant drop in bacterial numbers in comparison to the other temperatures tested $(P<0.001)$. However, bacterial growth at room temperature did occur in the following two hours, represented in figure 5 by a significant increase in $\log \mathrm{CFU} / \mathrm{ml}$ from the time of reconstitution $(P<0.05)$. At each testing interval the difference between the $70^{\circ} \mathrm{C}$ reconstituted PIF and the three other temperatures tested remained significant $(P<0.05)$. This indicates that even a small decrease in temperature from the recommended $70^{\circ} \mathrm{C}$ to $65^{\circ} \mathrm{C}$ would cause a significant increase in the survival rate of any intrinsic Cronobacter contamination in the PIF, subsequently increasing the risk of infection in the home/hospital setting. This drop of $5^{\circ} \mathrm{C}$ was found to occur after only a 5-10 minutes deviation from the recommended 30 minute cooling period (data not shown). It should be noted that Cronobacter contamination in PIF would likely be at much lower levels than are represented here. It is likely therefore, that the $\log$ reduction in bacterial numbers caused by the reconstitution at $70^{\circ} \mathrm{C}$ would be sufficient to completely eliminate the low levels of viable cells seen in contaminated batches of PIF. These findings emphasise the importance of complying with WHO recommendations for the safe preparation of PIF products and suggests that the current manufacturer instructions may be inadequate to prevent future outbreaks of Cronobacter infection. It is suggested that additional instructions regarding the use of a set volume of water and the checking of temperature with a sterile thermometer be adopted by manufacturers of PIF.

\section{CONCLUSION}

It can be concluded that that the temperature of water used for reconstitution has a very significant effect on the survival and growth of C.sakazakii (ATCC 29544) in PIF. Tolerance to heat treatment at $55^{\circ} \mathrm{C}$ for 10 minutes was found in multiple strains but was absent in some indicating that certain traits are strain dependent. Future research should include the effect of reconstitution temperature on biofilm formation and growth at $4^{\circ} \mathrm{C}$, factors which may also be contributing to the risk of infection from these organisms. It is recommended that manufacturers of PIF should review their instructions to consumers for the preparation of this product in order to ensure the lowest possible risk of infection from these opportunistic pathogens.

Acknowledgments: The author would like to acknowledge the Irish Research Council for funding this project. 


\section{REFERENCES}

AGOSTONI, C., AXELSSON, I., GOULET, O., Koletzko, B., MICHAELSEN, K., PUNTIS, J., RIGO, J., SHAMIR, R., SZAJEWSKA, H., TURCK, D., VANDENPLAS, Y., WEAVER, L. 2004. Preparation and Handling of Powdered Infant Formula: A Commentary by the ESPGHAN Committee on Nutrition. Journal of Pediatric Gastroenterology and Nutrition, 39, 320-322. http://dx.doi.org/10.1097/00005176-200410000-00002

BUSTA, F. 1978. Introduction to injury and repair of microbial cells. Advances in Applied Microbiology. Edited by A. Laskin. USA: Academic Press Inc. ISBN $0-12-002623-6$

FAO \& WHO. 2004. Enterobacter sakazakii and other microorganisms in powdered infant formula: Food and Agriculture Organisation and the World Health Organisation. Executive summary of the Joint FAO/WHO Workshop on Enterobacter Sakazakii and Other Microorganisms in Powdered Infant Formula, available at http://www.who.int/foodsafety/publications/micro/summary.pdf

HARSTELL, S. 1951. The longevity and behaviour of pathogenic bacteria in frozen food: the influence of plating media. American Journal of Public Health, 41, 1072-1077. PMCID: PMC1525859

IVERSEN, C., LANE, M., FORSYTHE, S. 2004. The growth profile, thermotolerance and biofilm formation of Enterobacter sakazakii grown in infant formula milk. Letters in Applied Microbiology, 38, 378-382. http://dx.doi.org/10.1111/j.1472-765X.2004.01507.X

IVERSEN, C., MULLANE, N., MCCARDELL, B., TALL, B. D., LEHNER, A., FANNING, S., STEPHAN, R., JOOSTEN, H. 2008. Cronobacter gen. nov., a new genus to accommodate the biogroups of Enterobacter sakazakii, and proposal of Cronobacter sakazakii gen. nov., comb. nov., Cronobacter malonaticus sp. nov., Cronobacter turicensis sp. nov., Cronobacter muytjensii sp. nov., Cronobacter dublinensis sp. nov., Cronobacter genomospecies 1, and of three subspecies, Cronobacter dublinensis subsp. dublinensis subsp. nov., Cronobacter dublinensis subsp. lausannensis subsp. nov. and Cronobacter dublinensis subsp. lactaridi subsp. nov. International Journal Of Systematic And $\begin{array}{llll}\text { Evolutionary } & \text { Microbiology, } & 58, & 1442-1447 .\end{array}$ http://dx.doi.org/10.1099/ijs.0.65577-0

JOSEPH, S., CETINKAYA, E., DRAHOVSKA, H., LEVICAN, A., FIGUERAS, M., FORSYTHE, S. J. 2011. Cronobacter condimenti sp. nov., isolated from spiced meat and Cronobacter universalis $s p$. nov., a novel species designation for Cronobacter sp. genomospecies 1, recovered from a leg infection, water, and food ingredients. International Journal of Systematic and Evolutionary Microbiology, $\quad 62, \quad 1277-1283$. http://dx.doi.org/10.1099/ijs.0.032292-0

KANG, D., FUNG, D. 2000. Application of thin agar layer method for recovery of injured Salmonella typhimurium. International Journal of Food Microbiology, 54, 127-132. http://dx.doi.org/10.1016/S0168-1605(99)00174-9

KIM, K., JANG, S., KIM, S. K., PARK, J.-H., HEU, S., RYU, S. 2008. Prevalence and genetic diversity of Enterobacter sakazakii in ingredients of infant foods. International Journal of Food Microbiology, 122, 196-203. http://dx.doi.org/10.1016/j.ijfoodmicro.2007.11.072

LIN, L., BEUCHAT, L. 2007. Survival of Enterobacter sakazakii in infant cereal as affected by composition, water activity, and temperature. Food Microbiology, 24, 767-777. http://dx.doi.org/10.1016/j.fm.2007.02.001

MULLANE, N. R., WHYTE, P., WALL, P. G., QUINN, T. \& FANNING, S. 2007. Application of pulsed-field gel electrophoresis to characterise and trace the prevalence of Enterobacter sakazakii in an infant formula processing facility. International Journal of Food Microbiology, 116, 73-81. http://dx.doi.org/10.1016/j.ijfoodmicro.2006.12.036

NAZAROWEC-WHITE, M. \& FARBER, J. 1997a. Enterobacter sakazakii: a review. International Journal of Food Microbiology, 34, 103-113. http://dx.doi.org/10.1016/S0168-1605(96)01172-5

NAZAROWEC-WHITE, M., FARBER, J. 1997b. Thermal resistance of Enterobacter sakazakii in reconstituted dried-infant formula. Letters in Applied Microbiology, 24, 9-13. http://dx.doi.org/10.1046/j.1472-765X.1997.00328.x

OSAILI, T., FORSYTHE, S. 2009. Desiccation resistance and persistence of Cronobacter species in infant formula. International Journal of Food Microbiology, 136, 214-220. http://dx.doi.org/10.1016/j.ijfoodmicro.2009.08.006 PAGOTTO, F., FARBER, J. 2009. Cronobacter spp. (Enterobacter sakazakii): Advice, policy and research in Canada. International Journal of Food Microbiology, 136, 238-245. http://dx.doi.org/10.1016/j.ijfoodmicro.2009.05.010 SCHMID, M., IVERSEN, C., GONTIA, I., Stephan, R., Hofmann, A., Hartmann, A., Jha, B., Eberl, L., Riedel, K., Lehner, A. 2009. Evidence for a plantassociated natural habitat for Cronobacter spp. Research in Microbiology, 160, 608-614. http://dx.doi.org/10.1016/j.resmic.2009.08.013

STRYDOM, A., CAWTHORN, D.-M., CAMERON, M., WITTHUHN, R. 2012. Species of Cronobacter - A review of recent advances in the genus and their significance in infant formula milk. International Dairy Journal, 27, 3-12. http://dx.doi.org/10.1016/j.idairyj.2012.06.005

WANG, X., MENG, J., ZHANG, J., ZHOU, T., ZHANG, Y., YANG, B., XI, M., XIA, X. 2012. Characterization of Staphylococcus aureus isolated from powdered infant formula milk and infant rice cereal in China. International
Journal of Food Microbiology,

153

$142-147$ http://dx.doi.org/10.1016/j.ijfoodmicro.2011.10.030

WU, V., FUNG, D. 2001. Evaluation of thin agar layer method for recovery of heat-injured foodborne pathogens. Journal of Food Science, 66, 580-583. http://dx.doi.org/10.1111/j.1365-2621.2001.tb04605.x

WU, V. 2008. A review of microbial injury and recovery methods in food. Food Microbiology, 25, 735-744. http://dx.doi.org/10.1016/j.fm.2008.04.011 